\title{
A Course in Manufacturing Systems with Simulation
}

\author{
William A. Kline \\ Rose Hulman Institute of Technology
}

abstract

The manufacturing sector plays a vital role in the national economy and the recent pressures of outsourcing and offshoring place a higher emphasis on excellence in manufacturing systems and manufacturing management to retain a competitive manufacturing sector in the United States. A course in manufacturing systems has been developed with the Factory Physics textbook and the Promodel simulation package.

The Factory Physics textbook presents a broad introduction to production processes with particular emphasis on batch process analysis and the role of variability on process performance. The book provides both philosophical perspectives of production principles and also fundamental analytical solutions for process performance parameters. As such, it provides a quantitative basis for discussion of strategies such as MRP, JIT, and lean manufacturing. In addition to textbook analytical solutions, the Promodel simulation package has been used in the class for students to build virtual simulation models of the production processes and verify their solutions. The combination of Factory Physics with Promodel provides an ideal learning environment for students by combining the textbook analysis with the hands-on experience of building and simulating the production system in Promodel. Students both build their own simulation solutions to problems as well as experiment with models provided by the instructor. Preliminary assessment data shows that students respond favorably to the combined textbook and simulation approach.

introduction

The manufacturing sector plays a vital role in the national economy and the recent pressures of outsourcing and offshoring have placed the sector under enormous stress. Since July 2000, some 2.8 million jobs in manufacturing have been lost and manufacturing employment has been in overall decline from its peak in $1979^{11}$. Despite the decline of the manufacturing sector since 2000 , the manufacturing sector still accounts for $13.8 \%$ of GNP and $10.5 \%$ of employment in the United States ${ }^{6}$. These recent and continuing trends of the decline of manufacturing place a higher emphasis on excellence in manufacturing systems and manufacturing management to retain a competitive manufacturing sector in the United States. A course in manufacturing systems has been developed with the Factory Physics textbook and the Promodel simulation package.

Many courses in manufacturing systems narrowly focus on metalworking and processing equipment. The Factory Physics textbook presents a broad introduction to production processes 
with particular emphasis on batch process analysis and the role of variability on process performance. The book provides both philosophical perspectives of production principles and also fundamental analytical solutions for process performance parameters. As such, it provides a quantitative basis for discussion of strategies such as MRP, JIT, and lean manufacturing. In addition to textbook analytical solutions, the Promodel simulation package has been used in the class for students to build virtual simulation models of the production processes and verify their solutions.

The combination of Factory Physics with Promodel provides an ideal learning environment for students by combining the textbook analysis with the hands-on experience of building and simulating the production system being studied in Promodel. The student version of Promodel is introduced early in the class and is used as a complement to class and homework problems to verify the textbook solutions. Building the Promodel solution forces students to think about and identify the process structure, connections, and parameters as they would in a real production setting. Students both build their own simulation solutions to problems as well as experiment with models provided by the instructor.

As the textbook does not integrate the simulation approach, several new homework assignments, case studies, and a student project covering generic production and logistics processes have been integrated into the course to illustrate course concepts.

Preliminary assessment data shows that students respond favorably to the combined textbook and simulation approach. Students generally rate the textbook as average to below average and the use of simulation helps to fill some of the perceived shortcomings of the book.

background on manufacturing systems courses

A course in 'manufacturing systems' may cover topics ranging from metalworking processes, computer applications in automated equipment ${ }^{4}$, to production system design with simulation $^{1,8,9}$, to a survey of management techniques such as lean manufacturing. Therefore, there appears to be no 'typical' course content for a manufacturing systems class. This paper describes the development of a manufacturing systems class focusing on widespread generic application, a management perspective yet with a strong technical focus, and quantitative analysis methods to serve as problem solving tools.

The manufacturing systems course has been developed for a quarter long (ten weeks) graduate level class in an Engineering Management program, but has also been offered as an elective course for undergraduates. Students in the program are typically working professionals early in their careers and representing a wide range of job responsibilities including design, manufacturing, and service and from a wide range of industry segments including automotive and suppliers, pharmaceutical, medical equipment, and chemical processing industries. A traditional class with a metalworking processes focus would have limited appeal. Based on this broad range of student interests, it was decided to create a manufacturing systems class with broad generic appeal focusing on process analysis techniques, quantitative analysis, and principles of manufacturing management. The prerequisites for the class are senior or graduate level standing with a previous introductory class in statistics. 
development of manufacturing systems course

A brief survey of textbooks on manufacturing systems was made and the Factory Physics, $2^{\text {nd }}$ Edition textbook ${ }^{3}$ was selected but not without some reservations. Hopp and Spearman view their book as the intersection of traditional 'operations management' and 'manufacturing' focusing on the higher level, technical manufacturing issues and not the lower level manufacturing process analysis. Hopp and Spearman draw parallels to the field of physics in that their book focuses on universal technical principles and not the latest buzzwords and further emphasize a problem-solving framework, technical approach, and the role of intuition. The perspective of the book is 'discrete parts production on disconnected flow lines' which refers to batches of discrete parts moving through separate workstations connected by material handling systems where queues of material may form before or after the workstations. The fundamental parameters defined and studied for the production process are cycle time, work in process, and throughput. These parameters are defined, derived, and studied for a variety of production scenarios.

Hopp and Spearman highlight the impact of variability on the performance of the production process, typically the negative impact. In addition to arrival and processing time variability, the authors include the effects of batching and downtime variability for setup and maintenance. These insights into the impacts of variability on the production process provide a satisfying complement to the traditional quality studies of variability. In quality studies, variations in materials, tools, and process settings are commonly investigated for their impacts on finished product measures and their deviation from specifications. The identification of the critical importance of the time related process variations provides an additional dimension and sources to be investigated for quality and process improvement.

The author is a wholehearted supporter of the book particularly for the tools to quickly characterize a process, the detailed analysis of the impact of variability in processes, and the overall quantitative approach taken. However, after reviewing the text and associated chapter problems and case studies, it was felt that it would be difficult to both support a graduate level class and successfully illustrate textbook concepts with the material available.

The ProModel simulation package (student edition) was selected to complement the textbook. Promodel provides discrete event manufacturing simulation capabilities in a Windows environment. The student version is available at a reasonable price, on CD with manual, and able to model all the homework and case problems assigned. The terminology and features of the program match reasonably well with the book. The standard process icons provided with the program are 'machine-shop' oriented but can be applied to any process. By combining the theoretical textbook concepts with the simulation tool, it is possible to present and discuss a theoretical textbook concept and then use the simulation tool to demonstrate and visualize the concept in a virtual manufacturing system. The focus on the impact of process variation in Hopp and Spearman placed emphasis on the statistical modeling capabilities of Promodel. Hopp and Spearman study the effects of variability on the mean level changes of process parameters such as cycle time and throughput. While simulation studies typically require the statistical analysis 
of results, the primary focus of the textbook and class is the impact of process variation on these mean level changes. The student version of Promodel was able to successfully model all homework and project assignments in a straightforward manner. In addition, there were no installation or operation problems with running the software on a variety of student computer systems.

General learning objectives identified for the course include the ability to identify the structure of a production process, understand and identify the common sources of variation, describe the common process performance parameters, apply Little's Law, and characterize the performance level of a process based on cycle time, work in process, and throughput levels.

Chapters covered in the ten week, quarter course are Chapters 1 and 3 through 10 with chapters 7-10 being the heart of the factory physics approach covering Basic Factory Dynamics, Variability Basics, and the Corrupting Influence of Variability. The table below lists the chapter coverage by week.

\begin{tabular}{|c|c|c|c|c|c|c|c|c|c|c|}
\hline Course Week & 1 & 2 & 3 & 4 & 5 & 6 & 7 & 8 & 9 & 10 \\
\hline Chapter & 1 & $3,4,5$ & 6 & 7 & 7 & 8 & 8 & 9 & 10 & 10 \\
\hline
\end{tabular}

Table 1 - Chapter Coverage by Class Week

The application of the ProModel simulation tool begins in Chapter 7 and is one of the reasons that two weeks are devoted to Chapters 7, 8, and 10. During the last week of the class, students make in-class project presentations. If these project presentations are omitted, another chapter of material could be covered, ideally Chapter 13 on 'A Pull Planning Framework'.

The ProModel simulation software is first applied to model and illustrate the behavior of the 'Penny Fab' production line. The Penny Fab production line is a simple four station production line with pennies moving through the line. The authors use this model to develop the concepts of a production system operating under best-case, practical worst case (PWC), or worst case conditions. Each case gives rise to different production system behavior and different equations that govern the cycle time, work in process, and throughput of the system. As an in-class exercise, students setup the Penny Fab production line at their desks with paper and pennies, assume different levels of work in process and manually operate the line by sliding pennies across the desktop. The students simulate the production line over many time periods to determine the behavior of cycle time and work in process for different levels of work in process. Through this hands-on exercise, the students illustrate the behavior of 'best case' production conditions and verify Little's Law as the relationship between cycle time, work in process, and throughput.

Beyond the desktop, hands-on simulation, the next in-class exercise is the creation of a simulation model for the Penny Fab 'best case' situation. This is equally 'hands-on' as the desktop model but in a virtual sense. This illustrates the creation of four locations as workstations, the connections between them and the introduction of entities as pennies moving through the system. A pictorial model of Penny Fab and the resulting simulation output is shown in Figures 1 and 2. The model is be executed for several hours and over the simulation time, an animated view of the process shows the entities moving through the system providing an 
intuitive and visual feel for the system behavior. The pace of the simulation and animation is easily controlled by a slider control. Through this simple model, students verify their results for cycle time and throughput as work in process varies to the results from their desktop simulation and Little's Law. From Figure 2, the work in process level is 3 pennies, the throughput rate is 0.375 pennies/hour ( 270 penny exits in 720 hours), the cycle time is 8 hours (481 average minutes in system), and the utilization of each workstation is $75 \%$.

As a homework assignment, the students take the model for the best case situation and modify it for the practical worst case and worst case situations. For the practical worse case model, the station processing times are changed from constant values to random variables with the exponential distribution. For the worst case situation, the transfer of entities or pennies is constrained to move as a batch through the system. This simple problem forces students to fully understand the assumptions and conditions for each production case and build or modify the simulation model for each of the conditions. Through the simulation model and animated output, students visualize the differences in efficiency, waiting times, and batch processing as pennies move through the models for the different cases.

Special homework assignments were created for Chapters 8, 9, and 10. In addition to the textbook problems emphasizing the equation based analysis and application approach, simulation based problems were developed to first build simple simulation models to verify the equation based solutions. In several cases, the simple models were modified or extended to explore differences in variability, batch sizes, or queue sizes. In addition to the equation based solutions, the students must go into the models and change the appropriate parameters or modify structure to represent the new conditions. This helps to build the intuitive feel between the problem, the equations, and the structure of the system.

As an example, starting with a basic $\mathrm{M} / \mathrm{M} / 1$ queue and given parameters of arrival rates and processing time, the students calculate utilization, cycle time, work in process, and throughput from the Chapter 8 equations. The students develop a simulation model and the Promodel screen view is shown for this case in Figure 3. The simulated and calculated results compare closely, Figure 4, although there is typically a slight difference between the two. This problem is extended to include blocking and to the $\mathrm{M} / \mathrm{M} / 4$ case.

In Chapter 10, students are given a simple simulation model for a production system and instructed to operate the system under an MRP, JIT, and CONWIP production strategy. In each case, the students modify the structure and parameters of the model to represent each production strategy and then compare the ease of management implementation and overall production system results.

A class project was assigned to allow students to study and analyze a more open-ended problem. The problem selected was the National Cranberry Cooperative case study ${ }^{7}$. This case is a traditional 'process analysis' case study. The students are given the assignment to develop a simulation model for the cranberry processing company and to analyze such issues as bottlenecks, adding capacity, throughput, customer wait times, and developing an overall management action plan. The case study was not developed to be implemented as a simulation model and is therefore vague and lacking some information. This forces students to identify 
needed information and to make reasonable assumptions as necessary. This case study was selected since it raises a number of manufacturing technical and management issues but is a nontraditional problem and illustrates the widespread applicability of textbook and class concepts.

A unifying video clip ${ }^{5}$ of a sporting goods production factory tour was shown early in the class (week 1) and at the end of the class (week 9). In the second viewing, the students have far greater ability to identify potential sources of process variations and improvements such as batching issues.

\section{outcomes}

The combined analytical and simulation approach provides students two opportunities to absorb class concepts, the first being the equation based approach and the second being the 'hands-on' simulation approach. Most students appreciate the combined approach and find it possible to quickly pick up the simulation tools along with the other class concepts even with no prior simulation experience. In one sense, the addition of the simulation analysis to the class is an additional level of complexity but only a few students commented that the simulation analysis was too complicated or should be a separate class. Early assessment data from two course offerings with 45 total students resulted in a 'quality of the learning experience' score of $4.39 / 5.00$ with 4.00 being 'above average'. Several negative comments about the textbook were received and the text received a score of $2.81 / 5.00$ with 3.00 being 'average' and $38 \%$ of students scored the text as below average or poor.

conclusions

Excellence in manufacturing management is a critical issue to retain a competitive manufacturing sector in the United States. A manufacturing systems class combining the Factory Physics textbook and the Promodel simulation package provides a broad based introduction to manufacturing management principles in quantitative terms. Combining the factory physics approach and simulation provide a methodology and a toolbox to address a wide range of manufacturing and process improvement problems from providing an intuitive understanding of basic principles to the ability to quantitatively study and model more complex situations.

references

[1] Attia, Farouk, Robert Seaker, and Jignesh Rathod, 'A Lean Manufacturing Educational Model: Flexible Low-Cost Linking of Manufacturing Planning to Customer Requirements,' Proceedings of the 2004 American Society of Engineering Education Annual Conference and Exposition.

[2] Falkenburg, Donald R. and Tina M. Harkin, 'Embedding Experience in Learning within Manufacturing Education,' Proceedings of the 2002 American Society of Engineering Education Annual Conference and Exposition, Session 3563. 
[3] Hopp, Wallace J. and Mark L. Spearman, Factory Physics, Foundations of Manufacturing Management, Second Edition, Irwin McGraw Hill, New York, 2001.

[4] Jack, Hugh, 'Teaching Integrated Manufacturing Systems with Programming,' Proceedings of the 2001 American Society of engineering Education Annual Conference and Exposition, Session 3663.

[5] Management Video Series, Volume IX, McGraw-Hill/Irwin, ISBN 0-07-287089-3.

[6] McKinnon, Ronald I., U.S. Fiscal Deficits and Lost Jobs in Manufacturing, Stanford Institute for Economic Policy Research, October 2004.

[7] Miller, Jeffrey G. and R. Paul Olsen, National Cranberry Cooperative, Harvard Business Review Case Study, \# 675014.

[8] Rossler, Paul, 'Toward Complete, Coherent Production System Design Experiences,' Proceedings of the 200x American Society of Engineering Education Annual Conference and Exposition.

[9] Sirinterlikci, Arif and Shah Galib Habib, 'Utilizing Manufacturing Process Simulation Tools as Instructional Aids,' Proceedings of the 2003 American Society of Engineering Education Annual Conference and Exposition, Session 3263.

[10] Stier, Kenneth W., John C. Fesler, and Todd Johnson, 'Teaching Lean Manufacturing Principles in a Capstone Course with a Simulation Workshop,' Proceedings of the 2003 American Society of Engineering Education Annual Conference and Exposition, Session 2163.

[11] The Facts About Modern Manufacturing, The Manufacturing Institute, National Association of Manufacturers (NAM), $6^{\text {th }}$ Edition.

[12] White, William L., Dianne M. Schuch-Miller, and Marie D. Lee, 'The Development of Manufacturing Case Studies,' Proceedings of the 2003 American Society of Engineering Education Annual Conference and Exposition, Session 1363.

[13] Zarrugh, M.Y., 'An Innovative Interdisciplinary Approach for Teaching Modern Manufacturing,' Proceedings of the 2002 American Society of Engineering Education Annual Conference and Exposition, Session 2463. 


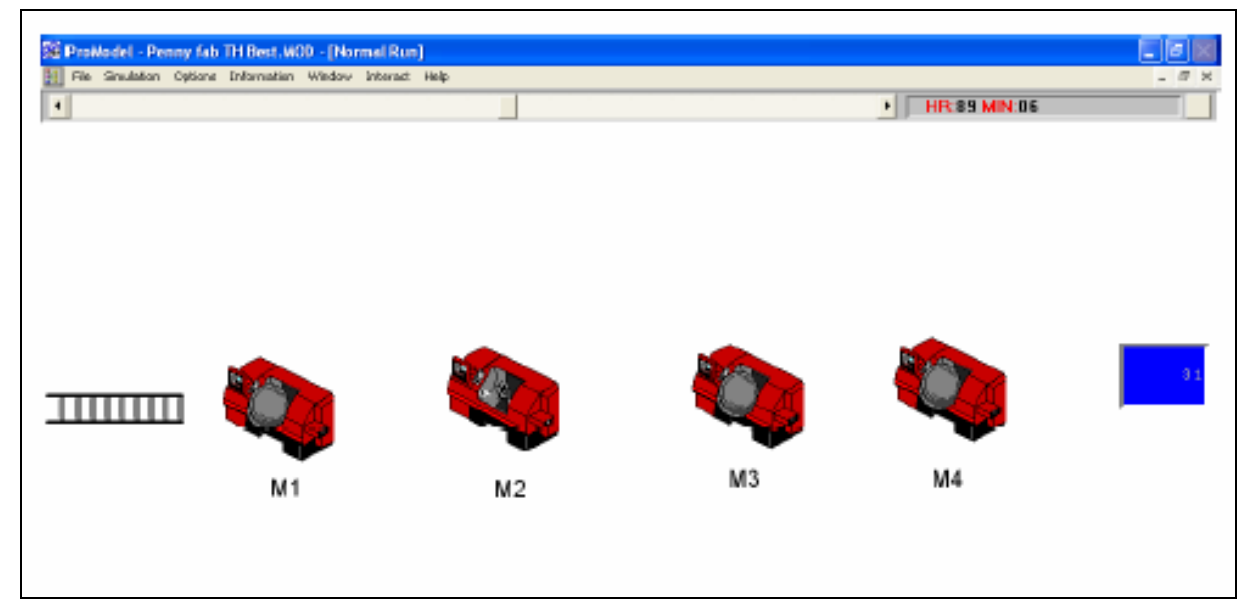

Figure 1 - ProModel Screen View for Penny Fab 


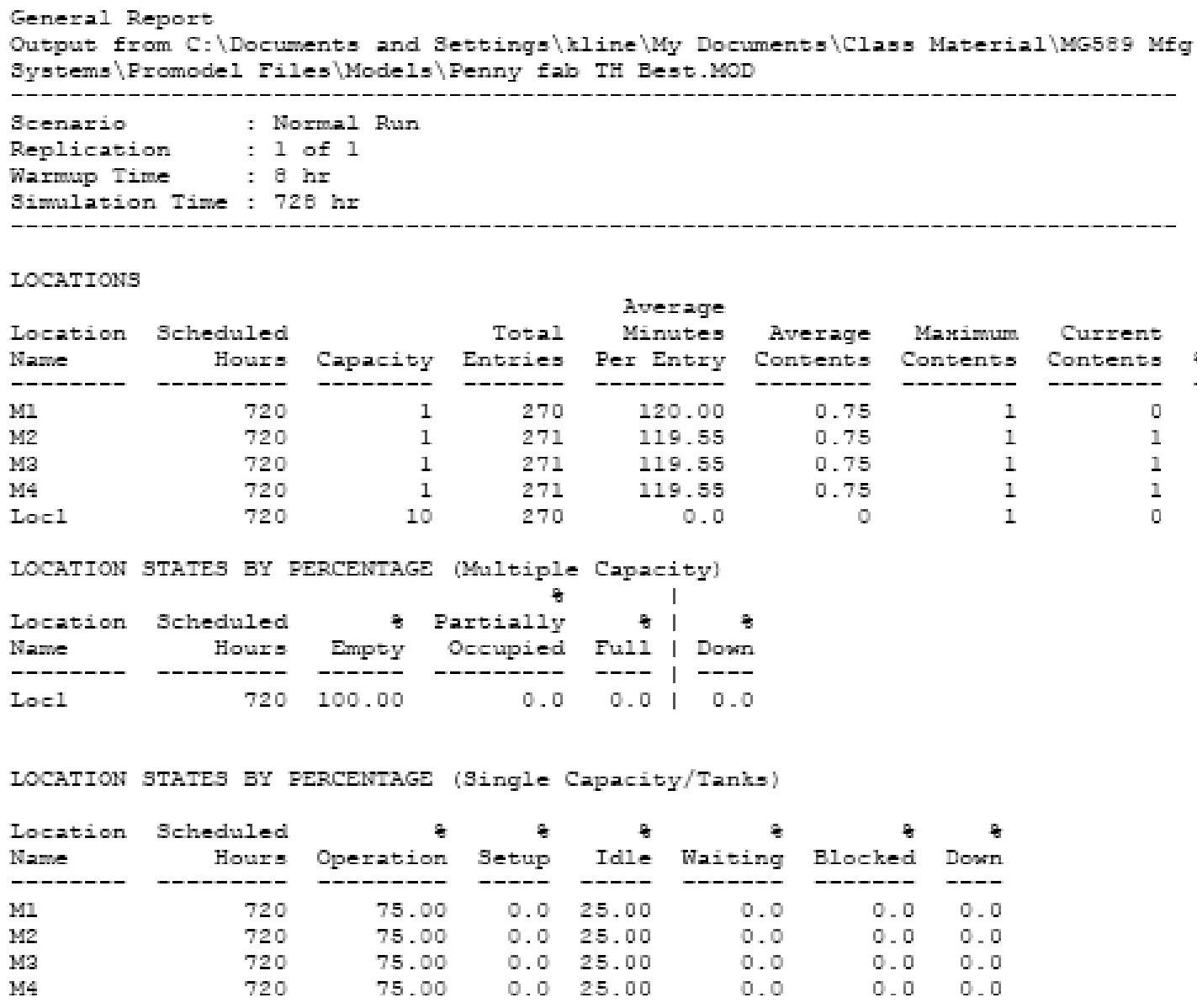

LOCATION STATES BY PERCENTAGE (Multiple Capacity)

\begin{tabular}{lrrrr|r} 
Location & $\begin{array}{r}\text { Scheduled } \\
\text { Hours }\end{array}$ & Empty & Partially & के | & Oceupied \\
Name & Hull & Down \\
\hline Loc1 & 720 & 100.00 & 0.0 & 0.0 & 0.0
\end{tabular}

IOCATION STRTES BY PERCENTAGE (Single Capacity/Tanks)

\begin{tabular}{|c|c|c|c|c|c|c|c|}
\hline $\begin{array}{l}\text { Location } \\
\text { Name }\end{array}$ & $\begin{array}{r}\text { Scheduled } \\
\text { Hours }\end{array}$ & Operation & Setup & Idie & Waiting & Blocked & Down \\
\hline - - - - & ---- & --n-n- & ----- & ---- & ----- & ----- & --- \\
\hline M1 & 720 & 75.00 & 0.0 & 25.00 & 0.0 & 0.0 & 0.0 \\
\hline M2 & 720 & 75.00 & 0.0 & 25.00 & 0.0 & 0.0 & 0.0 \\
\hline M3 & 720 & 75.00 & 0.0 & 25.00 & 0.0 & 0.0 & 0.0 \\
\hline M4 & 720 & 75.00 & 0.0 & 25.00 & 0.0 & 0.0 & 0.0 \\
\hline
\end{tabular}

Average Maximum Current Contents Contents Contents \& Util - - - - - - - - - - - - - $\begin{array}{llll}0.75 & 1 & 0 & 75.00\end{array}$ $\begin{array}{llll}0.75 & 1 & 1 & 75.00\end{array}$ $\begin{array}{llll}0.75 & 1 & 1 & 75.00\end{array}$

ENTITY ACTIVITY

\begin{tabular}{|c|c|c|c|c|c|c|c|}
\hline & & Current & $\begin{array}{l}\text { Average } \\
\text { Minutes }\end{array}$ & $\begin{array}{l}\text { Average } \\
\text { Minutes }\end{array}$ & $\begin{array}{l}\text { Average } \\
\text { Minutes }\end{array}$ & $\begin{array}{l}\text { Average } \\
\text { Minutes }\end{array}$ & $\begin{array}{l}\text { Average } \\
\text { Minutes }\end{array}$ \\
\hline intity & Total & Quantity & In & In Move & Wait For & In & \\
\hline Name & Exits & In Bystem & System & Logic & Res, ete. & Operation & Blocked \\
\hline enny & 270 & 3 & 481.33 & 0.0 & 0.44 & 480.00 & 0.88 \\
\hline
\end{tabular}

ENTITY STATES BY PERCENTAGE

\begin{tabular}{lrrrr} 
Entity & In Move & Wait Eor & के & के \\
Name & Logic & Res, ete. & In Operation & Blocked \\
\hline Penny & 0.0 & 0.09 & 99.72 & 0.18
\end{tabular}

Figure 2 - Promodel Text Output for Penny Fab Simulation - Best Case 


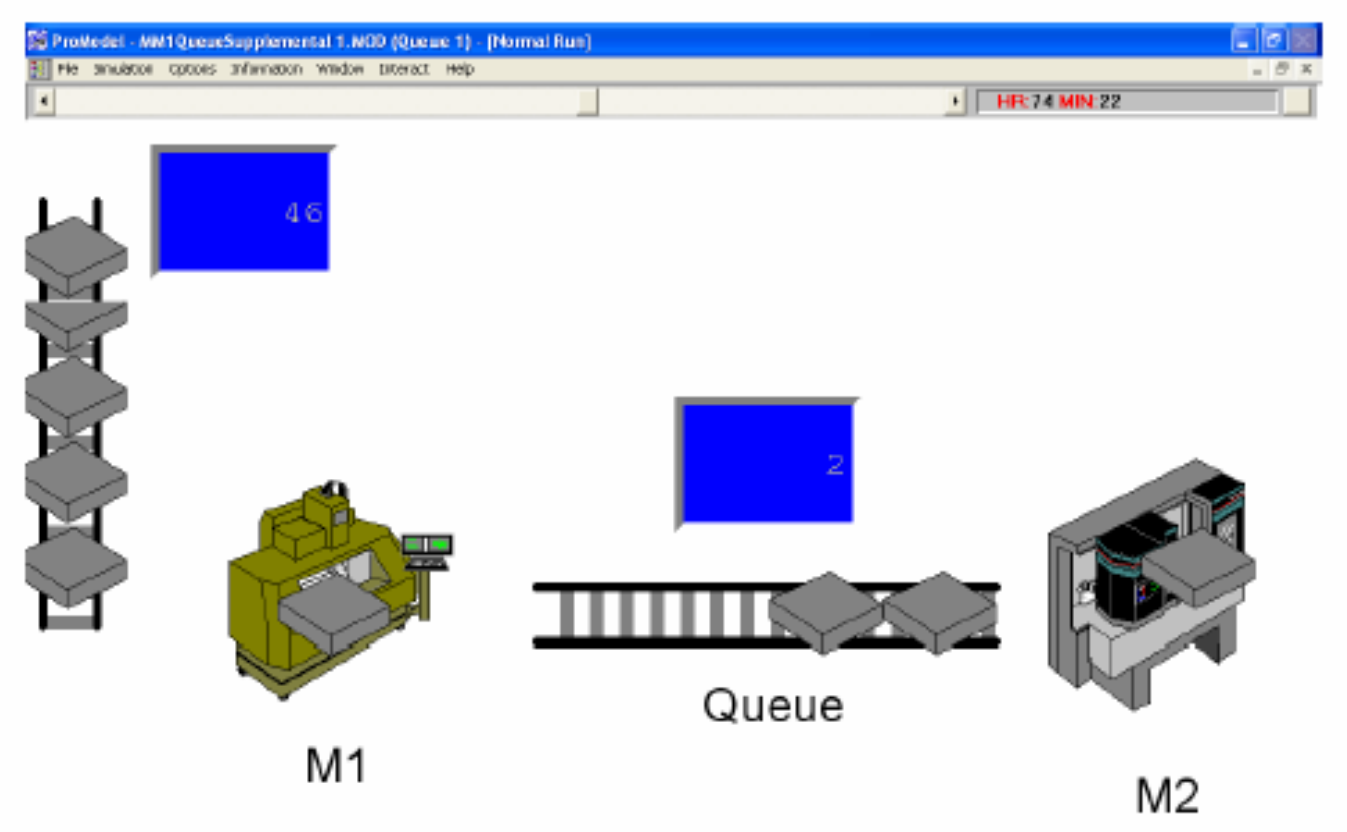

Figure 3 - ProModel Screen View for M/M/1 Queue

\begin{tabular}{|l|c|c|c|c|c|c|}
\hline \multicolumn{1}{|c|}{ Case } & $\mathrm{u}$ & $\mathrm{CT}$ & WIP & $\mathrm{CTq}$ & WIPq & TH \\
\hline Calculated & 0.775 & 13.78 & 3.44 & 10.68 & 2.67 & 0.25 \\
\hline Promodel Simulation & 0.778 & 13.72 & 3.41 & 10.6 & 2.64 & 0.249 \\
\hline
\end{tabular}

Figure 4 - Comparison of Calculated and Simulated Results for M/M/1 Queue 